\title{
Empathy, Compassion and Self-compassion in Psychology, Non- Psychology Students and Mindfulness Practitioners
}

\author{
Dinesh K. Ramoo ${ }^{a}$, Oshadhi Peiris ${ }^{b}$, Monika Albu \\ ${ }^{\mathrm{a} C ̧ a ̆ g ~ U n i v e r s i t y, ~}{ }^{\mathrm{b}}$ Coventry University, \\ ${ }^{c}$ Károli Gáspár University of the Reformed Church in Hungary
}

\begin{abstract}
Students who go into a profession such as psychology often characterize traits such as empathy and compassion to a higher degree than those outside those fields. However, they are also vulnerable to empathy- and compassion-fatigue which can lead to them being unable to provide compassion to both self and others (Beaumont et al., 2015). In countries such as Turkey and Sri Lanka, where psychology is an emerging field, understanding these traits in student populations can provide insight on how to provide support in these professions. Participants were recruited from Sri Lanka and Turkey divided into psychology students (Sri Lanka: n=25 Age M=22.5 $\mathrm{SD}=2.9$, Turkey: $\mathrm{N}=109$ Age $\mathrm{M}=21.4 \mathrm{SD}=1.2$ ) and non-psychology students (Sri Lanka: $\mathrm{N}=26$ Age $\mathrm{M}=27.3 \mathrm{SD}=9.4$, Turley: $\mathrm{N}=38$ Age $\mathrm{M}=20.4 \mathrm{SD}=1.6$ ). The Sri Lankan data also included Buddhist monks who practiced mindfulness meditation ( $\mathrm{N}=22$ Age $\mathrm{M}=20.4 \mathrm{SD}=4.9)$. The participants completed an empathy-compassion task and the Self-Compassion Scale (Neff, 2003). The study found no difference in empathy between the groups in either country, but there was a difference between psychology students in Sri Lanka and Turkey $t(198)=2.772, p=.006$. While there was no difference in compassion between the groups in Sri Lanka, there was a difference in Turkey $\mathrm{t}(126)=2.175, \mathrm{p}=.032$. There was difference for self-compassion in Sri Lanka $\mathrm{t}(49)=-2.332, \mathrm{p}=.024$ but not in Turkey. There was also a significant difference of selfcompassion between psychology students and Buddhist Monks in Sri Lanka (t(45)=-2.735, $\mathrm{p}=.009$ ). The results suggest that there is a need to support student psychologists in developing these traits.
\end{abstract}

Keywords: cross-cultural; compassion; empathy; mindfulness; self-compassion 